\title{
FORMULA OPTIMIZATION OF ORALLY DISINTEGRATING TABLET CONTAINING MELOXICAM NANOPARTICLES
}

\author{
Lina Winarti*, Lidya Ameliana, Dwi Nurahmanto
}

\begin{abstract}
Dept. of Pharmaceutical Technology, Faculty of Pharmacy, University of Jember, 37 Kalimantan St., Jember, East Java, 68121, Indonesia
\end{abstract}

Submitted: $12-08-2016$

Revised: 25-09-2016

Accepted: $10-01-2017$

*Corresponding author Lina Winarti

Email:

lina.winarti@unej.ac.id

\begin{abstract}
Meloxicam is one of the oxicam anti-inflammatory drugs that are effective to relieve toothaches, arthritis, dysmenorrhea, and fever. Meloxicam in this study was milled with High Energy Milling (HEM) method to obtain nano size and then direct compression method was used to produce Orally Disintegrating Tablet (ODT). ODT is designed to be rapidly dissolved on the tongue within a minute. It can be administered without water or chewing and may improve the bioavailability and effectiveness of the drug, and increase the patient's adherence. The present study aimed to understand the effects of Ac-Di-Sol and Kollidon $\mathrm{CL}$ as superdisintegrants, that were used separately or in combination, on the characteristics of nanoparticles meloxicam ODT. It was also to obtain the best proportion of combination between Ac-Di-Sol and Kollidon CL that can produce the optimum formula of meloxicam ODT. The effects of single or combined superdisintegrants were evaluated using Simplex Lattice Design (SLD). Ac-Di-Sol $\left(X_{1}\right)$ and Kollidon $\mathrm{CL}\left(\mathrm{X}_{2}\right)$ were independent variables, while dependent variables were friability $\left(Y_{1}\right)$, disintegrating time $\left(Y_{2}\right)$, wetting time $\left(Y_{3}\right)$, and percent meloxicam release after 60 seconds $\left(Y_{4}\right)$. Optimization of five nanoparticle meloxicam ODT formulas was conducted using Design Expert 7.1.5. The combination of Ac-Di-Sol $4.05 \mathrm{mg}\left(\mathrm{X}_{1}\right)$ and Kollidon CL $10.95 \mathrm{mg}\left(\mathrm{X}_{2}\right)$ in $150 \mathrm{mg}$ nanoparticles meloxicam ODT could produce optimal ODT characteristics. After verification, there was no difference between predicted value and observed value with $p$-value $>0.05$.
\end{abstract}

Keywords: orally disintegrating tablet (ODT), meloxicam, milling, nanoparticles

\section{INTRODUCTION}

Tablet is a solid dosage form convenience to carry, having a controllable duration of action. The taste and odor of the tablet can be improved by using certain techniques. However, geriatric and pediatric patients may experience difficulty in swallowing conventional tablets even with water (Koseki $e t$ al., 2009). Orally disintegrating tablet (ODT) benefits those patients because it rapidly dissolves in the mouth (Rahman et al., 2010). The volume of saliva required to disintegrate this type of tablet was minimum. The disintegrated tablet was then partly or completely absorbed into systemic circulation throughout blood vessels in the sublingual mucosa or it can be swallowed so that it dissolves and is absorbed in the gastrointestinal tract (Singh, 2009; Hirani et al., 2009).
Bioavailability of several drugs can be increased by ODT due to the increase of dissolution rate (Ahmed dan Aboul, 2007).

The primary criterion of ODT is rapid dissolution or disintegration inside the mouth, hence ODT should be ultimately formulated by direct compression method and contained high concentration of superdisintegrant. The concentration of superdisintegrant was determined based on the ODT characteristics, the amount of active ingredient, and desired drug release profile. Therefore, selecting appropriate type and amount of superdisintegrant are an important initial step in the ODT development (Camarco et al., 2006). In this research, two superdisintegrants Ac-Di-Sol and Kollidon CL were selected. Simplex Lattice Design was used to determine the optimum proportion of both 
superdisintegrants. The next criterion of ODT is the use of hydrophilic components, particularly the active ingredient (Sharma et al., 2005).

Meloxicam was used as the active component of ODT in this research. It is a non-steroidal anti-inflammatory drug (NSAID) that inhibits cyclo-oxygenase 2 (COX-2) and is used in the treatment of osteoarthritis and rheumatoid arthritis (Mahrouk et al., 2009). Meloxicam is classified under class II of Biopharmaceutics Classification System (BCS), having good permeability, but low solubility or practically insoluble in the water. Hence, the ODT formulation of meloxicam is a great challenge. The solubility of meloxicam in the water is $0.011 \mathrm{mg} / \mathrm{mL}$ (Saleem et al., 2010). An additional step is needed to increase the solubility of meloxicam, such as significantly reducing the particle size of meloxicam into nano size, which is widely known as nanoparticles.

Nanoparticles can be obtained using several methods and the most common one is media mill (Möschwitzher and Müller, 2007). Microparticles of meloxicam were turned into nanoparticles by using high energy milling (HEM) E3D. The nanoparticles were then evaluated using scanning electron microscope (SEM), particle size analyzer (PSA) dan X-ray diffraction (XRD). The particles yielded from milling were formulated to become ODT, which was then characterized using several tests including weight variation, uniformity of tablet content, hardness, friability, disintegrating time, wetting time, and in vitro dissolution.

Previous research studied the use of wet granulation to produce meloxicam ODT (Kulkarni et al., 2010), the use of sublimation (Elbary et al., 2012) and solid dispersion (Singhvi et al., 2013) methods to increase the dissolution rate of meloxicam ODT, and the use of ion exchange and complexation with cyclodextrin to mask the taste of meloxicam ODT (Samprasit et al., 2013). To the authors knowledge, literature search found no study that explores the effects of different superdisintegrants on the characteristics of nano-meloxicam ODT. Therefore, five formulas with different proportion of two superdisintegrants would be optimized in this study. The optimum formula would be verified and analyzed using OpenStat software.

\section{MATERIALS AND METHODS}

Meloxicam was purchased from Zhejiang Exel China and Ac-Di-sol was from FMCBiopolymer, Ireland. Kollidon CL was granted by BASF, Germany. Avicel pH 102 and aspartame were from Mingtai Chemical Co. Ltd., Taiwan and Vitasweet Co., Ltd., respectively. $\mathrm{Mg}$ stearate was ordered from Bratachem, Indonesia. Mannitol, talcum, and other compounds were either pharmaceutical or analytical grade.

\section{Preparation of meloxicam nanoparticles with High Energy Milling (HEM)}

An amount of $5 \mathrm{~g}$ meloxicam with a particle size of $4.057 \mu \mathrm{m}$ and ceramic balls with $2 \mathrm{~mm}$ of diameter were inserted into a chamber with 1:10 ratio. HEM E3D was then operated at $1400 \mathrm{rpm}$ for $48 \mathrm{~h}$ to yield meloxicam particles with size less than $1000 \mathrm{~nm}$. Particles of the product were characterized using scanning electron microscope (SEM), X-Ray diffractometer, and particle size analyzer (PSA).

\section{UV Spectrum analysis of meloxicam}

At first, a $100 \mu \mathrm{g} / \mathrm{mL}$ standard stock solution was prepared by inserting $10.0 \mathrm{mg}$ meloxicam into a $100.0 \mathrm{~mL}$ flask. $5.0 \mathrm{~mL}$ methanol and $1.0 \mathrm{~mL} \mathrm{NaOH} 0.1 \mathrm{~N}$ were then poured into the flask and this mixture was diluted with phosphate buffer $\mathrm{pH} 6.8$ up to $10.00 \mathrm{~mL}$. A $10 \mu \mathrm{g} / \mathrm{mL}$ solution for scanning was made from a $1.0 \mathrm{~mL}$ standard stock solution that was diluted with phosphate buffer $\mathrm{pH} 6.8$ up to $10.0 \mathrm{~mL}$. Because meloxicam absorbs UV at maximum $\lambda$ of $362 \mathrm{~nm}$, scanning was conducted at $\lambda 200-400 \mathrm{~nm}$.

\section{Calibration curve of meloxicam}

A standard curve was made by using a series of meloxicam concentration of $4,8,12$, 16,20 , and $24 \mu \mathrm{g} / \mathrm{mL}$ from the stock solution $100 \mu \mathrm{g} / \mathrm{mL}$. A UV/Visible spectrophotometer (Genesys 10UV Scanning, Thermo Electron Scientific Instrument Corporation, USA) was used to measure absorbance. A plot of absorbance and concentration was then made. 
Table I. Simplex lattice design for formulation

\begin{tabular}{lccccc}
\hline \multicolumn{1}{c}{ Materials (mg) } & F1 & F2 & F3 & F4 & F5 \\
\hline Nanoparticle meloxicam & $6.28^{*}$ & $6.28^{*}$ & $6.28^{*}$ & $6.28^{*}$ & $6.28^{*}$ \\
AC-Di-Sol & 15 & 3.75 & 0 & 7.5 & 11.25 \\
Kollidon CL & 0 & 11.25 & 15 & 7.5 & 3.75 \\
Avicel PH 102 & 100 & 100 & 100 & 100 & 100 \\
Mannitol & 24 & 24 & 24 & 24 & 24 \\
Aspartam & 2 & 2 & 2 & 2 & 2 \\
Magnesium stearate & 0.15 & 0.15 & 0.15 & 0.15 & 0.15 \\
Talcum & 1.35 & 1.35 & 1.35 & 1.35 & 1.35 \\
\hline TOTAL & $\mathbf{1 5 0}$ & $\mathbf{1 5 0}$ & $\mathbf{1 5 0}$ & $\mathbf{1 5 0}$ & $\mathbf{1 5 0}$ \\
\hline
\end{tabular}

*6.28mg meloxicam nanoparticles equal to $7.5 \mathrm{mg}$ meloxicam

\section{Preparation of nanoparticles meloxicam ODT}

ODT of nanoparticle meloxicam was formulated by using two superdisintegrants, Ac-Di-Sol and Kollidon CL, that were optimized by using Simplex Lattice Design and analyzed with Design Expert Software 7.1.5. The highest and the lowest level of each superdisintegrant were $15 \mathrm{mg}$ and $0 \mathrm{mg}$, respectively. Tablet was directly compressed according to formulas (Table I).

Each material was weighed, inserted into a mortar and then homogeneously mixed for 10min. Magnesium stearate and talc were the lubricants of the mixture. Pre-formulation characteristics of the homogeneous mixture were examined before being compressed with single punch machine (Korch PE 246 SRC, Germany).

\section{Bulk density}

Loose bulk density (LBD) and tapped bulk density (TBD) were measured using tapped density tester (Banker and Anderson, 1986).

Bulk density was calculated according to this equation:

$\frac{\text { Weight of Powder }}{\text { Tapped Volume }}$

Reduced volume due to tapping was stated as tapped density value:

Weight of Powder

Tapped Volume

Carr's index of mixed powder was calculated by using the following equation (Banker dan Anderson, 1986):
Carr's index $(\%)=\frac{((\mathrm{TBD}-\mathrm{LBD}) * 100)}{\mathrm{TBD}}$

Where, $\mathrm{LBD}=$ weight of powder/bulk volume of powder; TBD = weight of powder/tapped volume.

\section{Hausner Ratio}

Hausner ratio is an indirect index to evaluate the characteristics of powder flow, and it is calculated by using the equation below:

Hausner ratio $=\frac{\text { Tapped Density }}{\text { Bulk Density }}$

The Hausner ratio value of less than 1.25 indicates that powder flow is good (Bhowmik et al., 2009).

\section{Evaluation of water absorption capacity of mixed powder (Granules)}

Water absorption capacity tester was connected with electronic balance on which an infusion bag was set up above it. The position of the infusion bag inside the balance was carefully set up so that the bag did not touch the capillary pipe that was connected to the granules. The bag was filled with water until the height of its surface was at the same level with the surface of water inside the tube. Filter paper was placed on the tube and also above the granule holder. The amount of reduced water from ampoule (ARWFA) after $15 \mathrm{~min}$ was recorded.

$$
\text { Water Absorption Rate }=\frac{\text { ARWFA }}{\text { Absorption Time }}
$$




\section{Characterization meloxicam ODT \\ Average weight and weight variation}

A number of 20 tablets from each formula was weighed one by one using analytical balance. The average weight, coefficient of variation, and standard deviation was calculated (Indonesia Pharmacopeia, 2014).

\section{Evaluation of Content Uniformity}

A number of ten tablets from each formula were taken, powdered one by one and then inserted into a $100.00 \mathrm{~mL}$ beaker glass. Five $\mathrm{mL}$ of methanol and $1.0 \mathrm{~mL}$ of $\mathrm{NaOH}$ $0.1 \mathrm{~N}$ was added to the beaker and then diluted with phosphate buffer with $\mathrm{pH} 6.8$ up to $100.00 \mathrm{~mL}$. The concentration was measured with a UV spectrophotometer. The average concentration and coefficient of variation were calculated (Indonesia Pharmacopeia, 2014).

\section{Hardness Test}

Hardness test was carried out using Stokes Monsato hardness tester by taking six tablets randomly from each formula. The hardness value was measured and stated as mean + SD. A good ODT formulation should have hardness value in a range of $3-5 \mathrm{~kg} / \mathrm{cm}^{2}$ (Panigrahi dan Behera, 2010).

\section{Friability Test}

A number of 20 nanoparticle meloxicam ODT tablets were dedusted and weighed to define its initial weight. The friability tester (Erweka friabilator abrasive tester, Erweka type T.A.P, Germany) was rotated at a speed of $25 \mathrm{rpm}$ for $4 \mathrm{~min}$. The tablets were dedusted and weighed again to obtain their final weight (Lachman et al., 1994). The friability of tablet was calculated according to the following equation:

$\%$ Friability $=\frac{\text { Initial Weight }- \text { Final Weight }}{\text { Initial Weight }} \times 100$ (6)

\section{Disintegration Test}

Tablets were sunk in a 10 -cm-diameterpetri dish containing $10 \mathrm{~mL}$ water with a temperature of $25^{\circ} \mathrm{C}$. Disintegrating time of each of six tablets was recorded and the average value was calculated later (Gohel et al., 2004).

\section{Wetting Time}

A filter paper was folded twice and put on a 5 -cm-diameter-petri dish containing $5 \mathrm{~mL}$ aqua dest with FDC strawberry red/methylene blue dye. A tablet was gently placed on the filter paper. The time needed for the tablet surface to become red/blue was noted as wetting time. The test was repeated three times (Tanuwijaya et al., 2014).

\section{In vitro dissolution study}

The study was undertaken by placing ODT into a $900 \mathrm{~mL}$ dissolution medium, which was phosphate buffer $\mathrm{pH}$ 6.8, using USP type II apparatus (Erweka type D-63150, Germany) at $50 \mathrm{rpm}$ and $37 \pm 0.5^{\circ} \mathrm{C}$. Sampling was performed during the $1^{\text {st }}, 3^{\text {td }}, 5^{\text {th }}, 10^{\text {th }}, 15^{\text {th }}, 20^{\text {th }}$, $25^{\text {th }}$, and $30^{\text {th }}$ min by taking a $5.0 \mathrm{~mL}$ medium, filtering it, and pouring fresh $5.0 \mathrm{~mL}$ medium into the dissolution chamber. Absorbance was measured at $\lambda 361.5 \mathrm{~nm}$ using a UV-Vis spectrophotometer (Genesys 10UV Scanning, Thermo Electron Scientific Instrument Corporation, USA). The concentration of drug release was calculated (Indonesia Pharmacopea, 2014).

\section{RESULTS AND DISCUSSION}

Analysis of Meloxicam Nanoparticle Size

Initial results of measurement of meloxicam particle showed its size of $4057.4 \mathrm{~nm}$ with monodisperse characteristic. Milling was performed to decrease the particle size of meloxicam until it reached $<1 \mu \mathrm{m}$. This may improve the solubility of meloxicam as it would be formulated to become rapid dissolving tablet.

Measured by Particle Size Analyzer (DelsaTM Nano, Beckmann Coulter), milled meloxicam powder showed particle size reduction from $4057.4 \mathrm{~nm}$ to $372.6 \mathrm{~nm}$ with polydispersity index of 0.295 (Figure 1). This proves that milling can reduce the particle size of meloxicam and therefore it can be expected that solubility, bioavailability, and the onset of action of meloxicam will be more rapid to relieve pains due to arthritis or rheumatic diseases, for instances. 


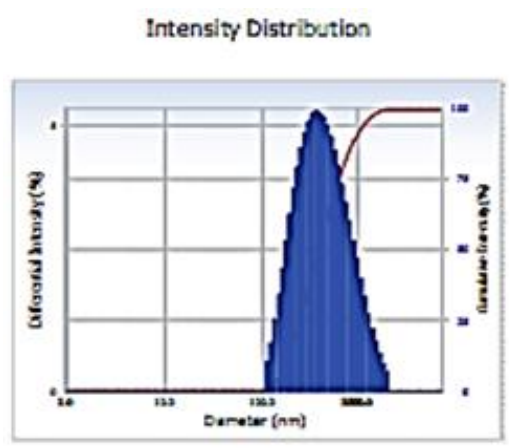

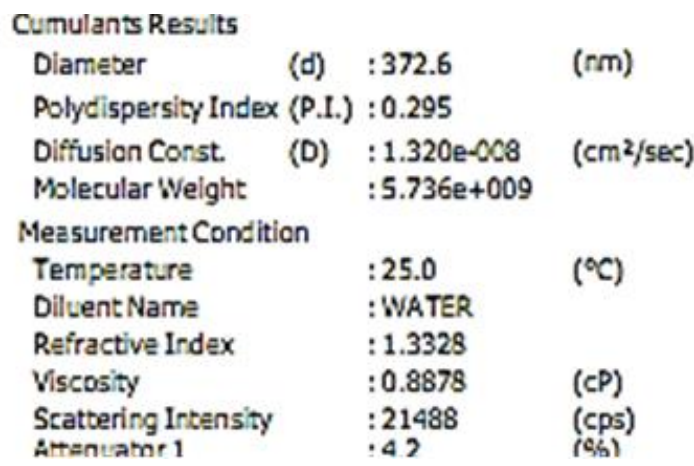

Figure 1. Particle size of meloxicam after treatment with HEM, measured with PSA
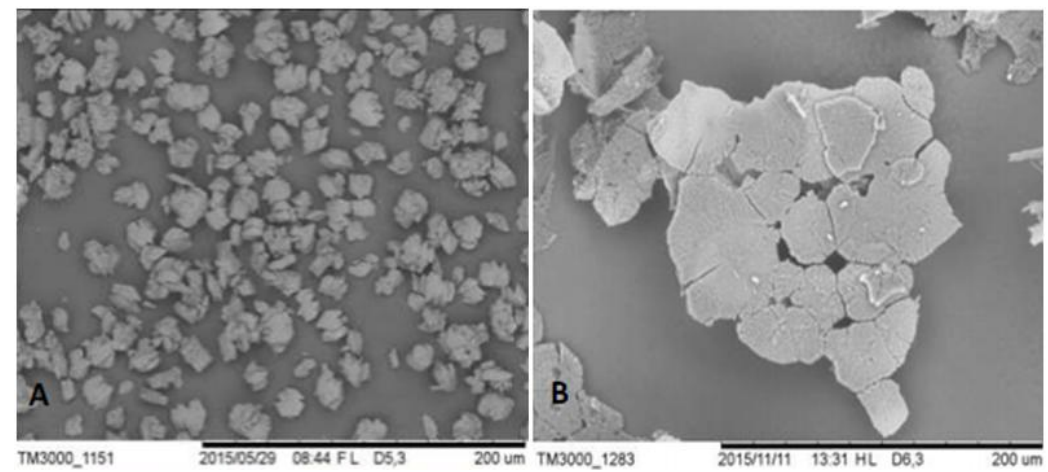

Figure 2. (A) Microparticles of meloxicam, 500x magnification (B) Nanoparticles of meloxicam, 500x magnification

\section{Morphological analysis of particles of nanoparticle meloxicam}

Morphological analysis of meloxicam particles was done with Scanning Electron Microscopy (SEM). Meloxicam particles appeared coarse and amorphous (Figure 2). SEM analysis was also used to examine whether morphological changes of meloxicam happened after milling. Figure 2 (B) shows that aggregation of meloxicam nanoparticles occurred, resulting in a seemingly greater size of nanoparticles than macroparticles.

\section{Analysis of meloxicam nanoparticles with XRD}

X-Ray diffraction showed that both meloxicam microparticles and nanoparticles had five peaks in the areas of 10-30 degrees (20). The similarity between both demonstrated that the particles being analyzed were meloxicam (Figure 3). The differences between both were on intensity and width of the peaks. These proved that milling can change the particle size. Widened peak indicates smaller crystal size. The reduction of crystal size may because of conduction or loss of mechanical energy during milling process (Bustos et al., 2007).

\section{UV spectrum analysis of meloxicam}

The maximum $\lambda$ of meloxicam was found $364 \mathrm{~nm}$ from UV scanning. Good standard curve requires a five-seriesconcentration in which linearity is the ability of an analytical procedure to result in proportional absorbance response or having a good correlation with analyte concentration within a defined range (ICH, 2005). The analytical method is said to be linear if within a certain range it has a correlation coefficient ( $\mathrm{r}$ ) $>0.99$ and determination coefficient $\left(\mathrm{R}^{2}\right) \geq 0.995$. Figure 4 shows a linear regression equation of $\mathrm{y}=0.0581 \mathrm{x}-0.0271$ with $\mathrm{R}^{2}=0.9982$. As those two values were close to 1 , it can be concluded that there was a strong correlation between analyte and response. 


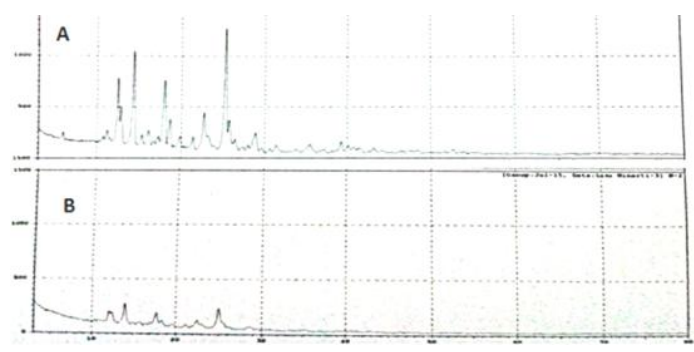

Figure 3. X-Ray diffraction of (A) meloxicam microparticles and (B) nanoparticles

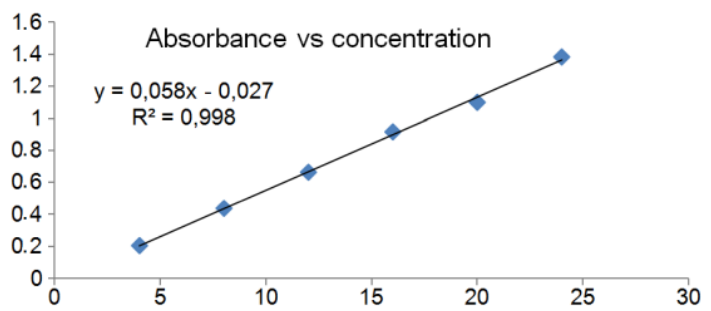

Figure 4. Standard curve of meloxicam

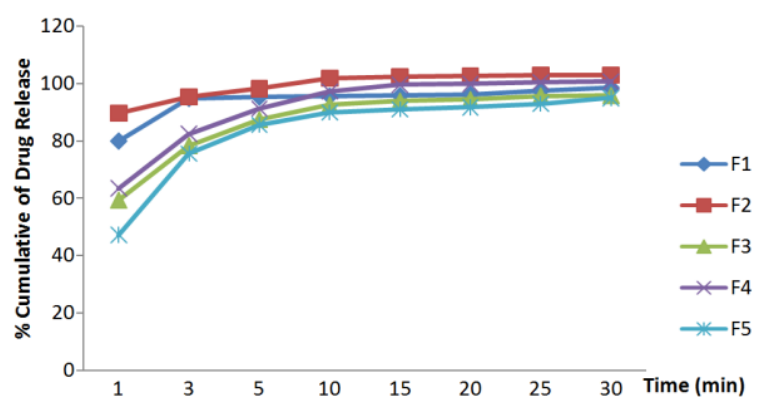

Figure 5. Comparative drugs release profile of five ODT formulations

\section{Evaluation of flow of granules and water absorption capacity}

Before being compressed to become tablets, the characteristics of homogenized granules were examined (Table II). The bulk density of granules was in a range of $0.38 \pm 0.02$ to $0.41 \pm 0.01$, whilst the tapped density was in between $0.48 \pm 0.01$ and $0.51 \pm 0.00$. Carr's index value of F1-F5 showed satisfactory flow properties (Banker dan Anderson, 1986), and therefore they suited to be processed into an orally disintegrating tablet by direct compression method. Hausner ratio that was in between $1.24 \pm 0.02$ to $1.28 \pm 0.05$ also indicated good flow properties.

Water absorption capacity affects disintegration process of tablets. Among five formulas of pre-compression granules (Table II), the formula with single superdistegrants Ac-Di-Sol (F1) had the highest rate of water absorption. This is because Ac-Di-Sol is a croscarmellose sodium that its structure is built from glucose polymer so that it has a great capacity to absorb water and rapidly swells. On the other hand, Kollidon CL is a crospovidone that has a hygroscopic cross-linking polymer that increases water absorption capacity of granules (Quadir dan Kolter, 2006).

\section{Evaluation of physical parameter of meloxicam nanoparticles ODT Weight variation}

The weight variation of ODT complied with the requirements of the $3^{\text {rd }}$ edition of Indonesia Pharmacopeia stating that among tablets with a weight of $150 \mathrm{mg}$ each, there cannot be two or more tablets that have $10 \%$ deviation or a tablet that has $20 \%$ deviation from the average weight. In fact, the coefficient of variation of all formulas was $<2 \%$ 
Table II. Evaluation results of granules flow and water absorption capacity

\begin{tabular}{cccccc}
\hline $\begin{array}{c}\text { Formula } \\
\text { Name }\end{array}$ & $\begin{array}{c}\text { Bulk Density } \\
(\mathbf{g} / \mathbf{m L})\end{array}$ & $\begin{array}{c}\text { Tapped Density } \\
(\mathbf{g} / \mathbf{m L})\end{array}$ & $\begin{array}{c}\text { Carr's Index } \\
\mathbf{( \% )}\end{array}$ & $\begin{array}{c}\text { Hausner's } \\
\text { Ratio }\end{array}$ & $\begin{array}{c}\text { Water absorption } \\
\text { capacity }(\mathbf{g} / \mathbf{m i n})\end{array}$ \\
\hline 1 & $0.41 \pm 0.01$ & $0.51 \pm 0.00$ & $19.17 \pm 1.44$ & $1.24 \pm 0.02$ & $0.12 \pm 0.00$ \\
2 & $0.38 \pm 0.02$ & $0.48 \pm 0.01$ & $20.00 \pm 2.50$ & $1.25 \pm 0.04$ & $0.09 \pm 0.01$ \\
3 & $0.39 \pm 0.01$ & $0.49 \pm 0.01$ & $20.00 \pm 2.50$ & $1.25 \pm 0.04$ & $0.08 \pm 0.00$ \\
4 & $0.39 \pm 0.00$ & $0.50 \pm 0.02$ & $21.67 \pm 2.89$ & $1.28 \pm 0.05$ & $0.08 \pm 0.02$ \\
5 & $0.39 \pm 0.00$ & $0.50 \pm 0.02$ & $21.67 \pm 2.89$ & $1.28 \pm 0.05$ & $0.06 \pm 0.00$ \\
\hline
\end{tabular}

Table III. Physical characteristics of Nanoparticle meloxicam ODT

\begin{tabular}{lrrrrr}
\hline \multirow{2}{*}{\multicolumn{1}{c}{ Parameter }} & \multicolumn{6}{c}{ F1 } & \multicolumn{1}{c}{ F2 } & \multicolumn{1}{c}{ F3 } & \multicolumn{1}{c}{ F4 } & \multicolumn{1}{c}{ F5 } \\
\cline { 2 - 6 } & $149.30 \pm 1.08$ & $149.75 \pm 1.12$ & $150.05 \pm 0.94$ & $149.90 \pm 1.06$ & $150.25 \pm 1.33$ \\
\hline Weight variation (mg) & 0.007 & 0.007 & 0.006 & 0.007 & 0.009 \\
CV of Tablets weight (\%) & $102.77 \pm 4.28$ & $102.53 \pm 3.46$ & $101.64 \pm 2.99$ & $104.22 \pm 2.27$ & $98.02 \pm 4.45$ \\
Drug Content (\%) & $4.17 \pm 0.14$ & $4.12 \pm 0.12$ & $4.15 \pm 0.10$ & $4.13 \pm 0.12$ & $4.12 \pm 0.10$ \\
Hardness (kg/cm $\left./ \mathrm{cm}^{2}\right)$ & $1.03 \pm 0.34$ & $0.66 \pm 0.04$ & $0.75 \pm 0.21$ & $0.63 \pm 0.19$ & $0.67 \pm 0.29$ \\
Friability (\%) & $17.50 \pm 1.44$ & $14.45 \pm 2.61$ & $17.31 \pm 1.21$ & $13.28 \pm 0.66$ & $14.25 \pm 1.25$ \\
Disintegration Time (s) & $8.72 \pm 0.14$ & $23.60 \pm 0.26$ & $27.23 \pm 0.72$ & $16.06 \pm 0.98$ & $12.99 \pm 0.97$ \\
Wetting Time (s) & & & & & \\
Cumulative of meloxicam & $79.85 \pm 3.32$ & $89.52 \pm 3.82$ & $59.15 \pm 5.97$ & $63.4 \pm 3.96$ & $47.08 \pm 3.28$ \\
released at 60 seconds (\%) & & & & & \\
\hline
\end{tabular}

(Indonesia Pharmacopeia, 2014), as shown in Table III. This is due to the satisfactory flow characteristics of all formulas that ensure the uniformity of powder entering the die.

\section{Content uniformity of meloxicam ODT}

The present content uniformity test aimed to know whether the content of each meloxicam ODT is in line with the requirements in the monograph. If the ODT fails to meet the requirements, its therapeutic effectiveness will not be achieved. The results showed that the average weight of meloxicam in all formulas (Table III) ranged between $98.02 \pm 4.45 \%$ and $104.22 \pm 2.27 \%$, thus meeting the requirements of the USP XXXVII (2014) that suggests meloxicam must be in a range of $90-110 \%$.

\section{Tablet hardness}

Tablet hardness is a parameter that represents the overall tablet resistance towards mechanical forces due to crash or collision with other objects during packaging, storage, and distribution to consumers. The hardness is also associated with disintegrating time. ODT hardness, approximately $3-5 \mathrm{~kg} / \mathrm{cm}^{2}$, is lower than conventional tablets, approximately 4$8 \mathrm{~kg} / \mathrm{cm}^{2}$ (Panigrahi dan Behera, 2010). The results from all formulas met the requirements in a range of $3-5 \mathrm{~kg} / \mathrm{cm}^{2}$ (Table III). It can be concluded that the nano-meloxicam ODT was fairly resistant to the mechanical collision.

\section{Effect of independent variables on friability}

Tablet friability represents the strength of particle bonding on the tablet surface to the effects of friction or abrasion. The friability of a tablet must not be more than 1\% (Panigrahi dan Behera, 2010). The results demonstrated that all formulas met the friability requirement (Table III).

Friability data in Table III can be made in an equation which can be seen at Table IV and the contour plot can be seen at Figure 6 . According to the equation (7), Ac-Di-Sol increased friability more than Kollidon CL. The combination of both reduced friability, indicated by the negative sign in the equation. Hence, it is understood that the use of Ac-DiSol in higher percentage may yield a tablet with 
Tabel IV Effect of independent variables in equation

\begin{tabular}{cc}
\hline Parameter & Equation \\
\hline Tablet friability $(\%)$ & $\mathrm{Y}_{1}=1.00 * \mathrm{~A}+0.77 * \mathrm{~B}-1.11 * \mathrm{~A} * \mathrm{~B} \ldots \ldots . .(7)$ \\
Wetting time (second) & $\mathrm{Y}_{2}=8.19 * \mathrm{~A}+27.25 * \mathrm{~B} \ldots \ldots .(8)$ \\
Disintegrating time (second) & $\mathrm{Y}_{3}=17.45 * \mathrm{~A}+17.37 * \mathrm{~B}-16.41 * \mathrm{~A} * \mathrm{~B} \ldots \ldots . .(9)$ \\
Cumulative drug release in $60 \mathrm{~s}(\%)$ & $\log \mathrm{Y}_{4}=1.9 * \mathrm{~A}+1.77 * \mathrm{~B}-0.14 * \mathrm{~A} * \mathrm{~B}-1.84 * \mathrm{~A} * \mathrm{~B} *(\mathrm{~A}-\mathrm{B}) \ldots \ldots .(10)$ \\
\hline
\end{tabular}

Where $\mathrm{A}=$ number of Ac-Di-Sol used, $\mathrm{B}=$ number of Kollidon CL used.

Table V. The values from four parameters of ODT

\begin{tabular}{cccc}
\hline Name & Goal & Lower limit & Upper limit \\
\hline Friability (\%) & Minimize & 0.63 & 1 \\
Disintegrating Time & Minimize & 13.28 & 30 \\
Wetting Time & Minimize & 8.72 & 60 \\
$\%$ Cumulative of meloxicam release in 60s & Maximize & 47.08 & 100 \\
\hline
\end{tabular}

Table VI. Optimum formula and verification results with predicted and observed experimental values analyzed using OpenStat software

\begin{tabular}{cccc}
\hline Parameter & Predicted values & Experimental values & p-value \\
\hline Friability (\%) & 0.62 & $0.63 \pm 0.32$ & 0.96 \\
Wetting Time (sec) & 22.10 & $22.60 \pm 0.25$ & 0.07 \\
Disintegrating Time (sec) & 14.16 & $14.28 \pm 0.36$ & 0.62 \\
$\%$ Cumulative of drug release in 60s & 88.48 & $89.06 \pm 0.42$ & 0.14 \\
\hline
\end{tabular}

high \% of friability (Wiradjaja et al., 2015). Model terms for friability were found to be insignificant on a quadratic model with $\mathrm{F}$ value of 13.15 dan p-value of 0.071 , which is more than 0.05 . However, all formulas had $\%$ friability less than $1 \%$, which fulfilled the requirement.

\section{Effect of independent variables on wetting time}

The shorter the wetting time, the easier a tablet to disintegrate (Hirani et al., 2009). All five formulas showed wetting time was less than a minute (Table III), and therefore it can be expected that they could readily disintegrate after they were placed in the mouth. Wetting time data in Table III can be made in equation (Table IV). The contour plot of wetting time can be seen in Figure 6.

According to the equation (8), Kollidon $\mathrm{CL}$ was more dominant than Ac-Di-Sol in accelerating the wetting process because Kollidon CL is hygroscopic and has the porous structure that facilitates water absorption (Mohamed et al., 2012; Kornblum and Stoopak,
1973). The model term showed a significant relationship, with $\mathrm{F}$ value of 158.97 and $\mathrm{p}$-value of 0.0011 , which was less than 0.05 .

\section{Effect of independent variables on disintegration time}

ODT is design to provide fast action. It is therefore must be rapidly disintegrated inside the mouth (Panigrahi dan Behera, 2010). The US FDA recommends disintegration time for ODT must be less than or equals to 30 seconds, as stated in the USP disintegration test (FDA Guidance, 2008). All formulas in the present study had disintegration time $<30$ s (Table III). Disintegration time data in Table III can be made in an equation. The equation (Table IV) and the contour plot of disintegration time ( Figure 6).

Quadratic model term showed a significant relationship with $\mathrm{F}$ value $=407.17$ and $\mathrm{p}$-value $=0.0024$. The use of single superdisintegrant, either Ac-Di-Sol or Kollidon CL, accelerated disintegration time, indicated by the positive sign in the equation (9), hence the onset 

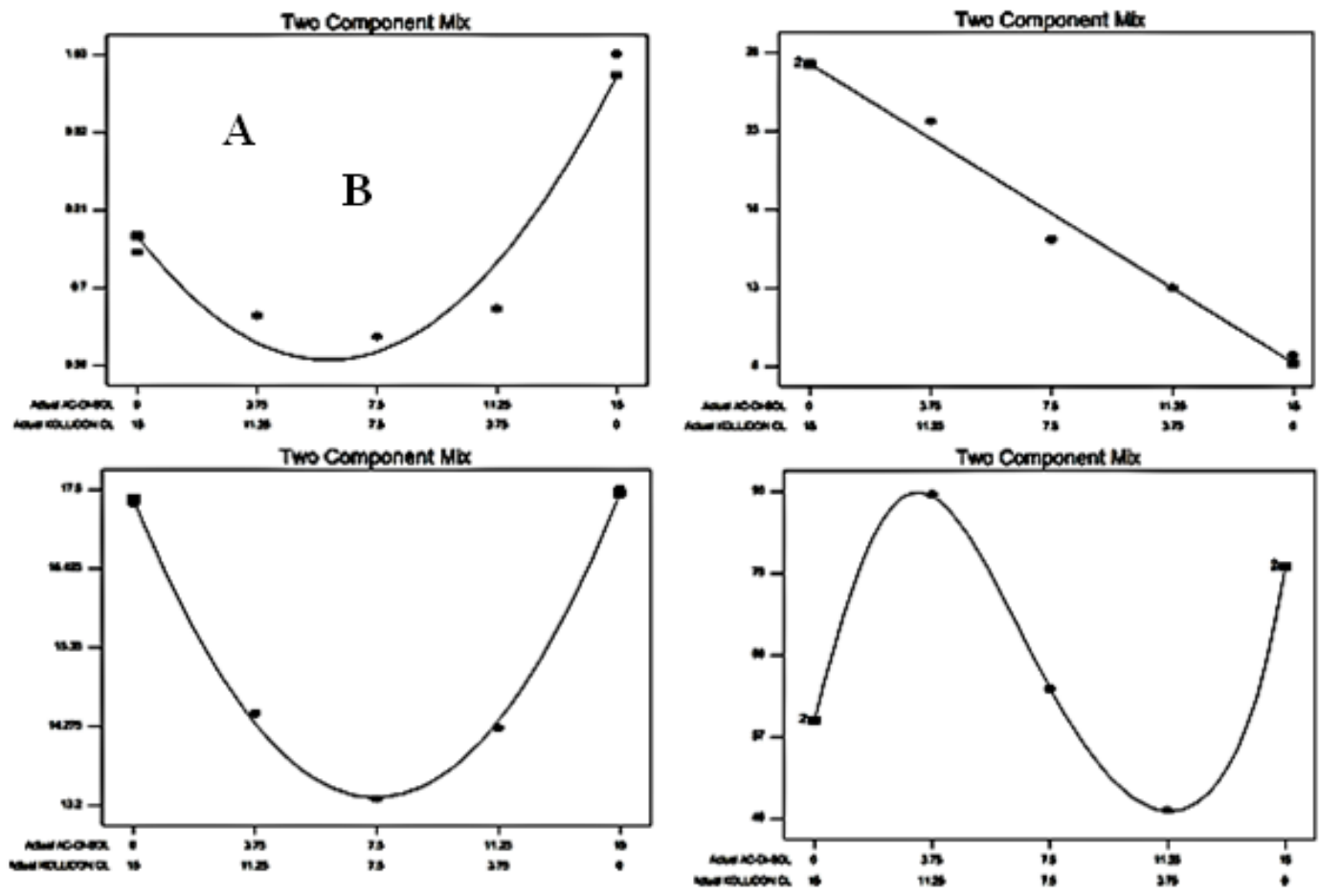

Figure 6. Contour Plot of (A) Friablity; (B) Wetting Time; (C) Disintegrating Time; (D) \% Cumulative of meloxicam release in $60 \mathrm{~s}$

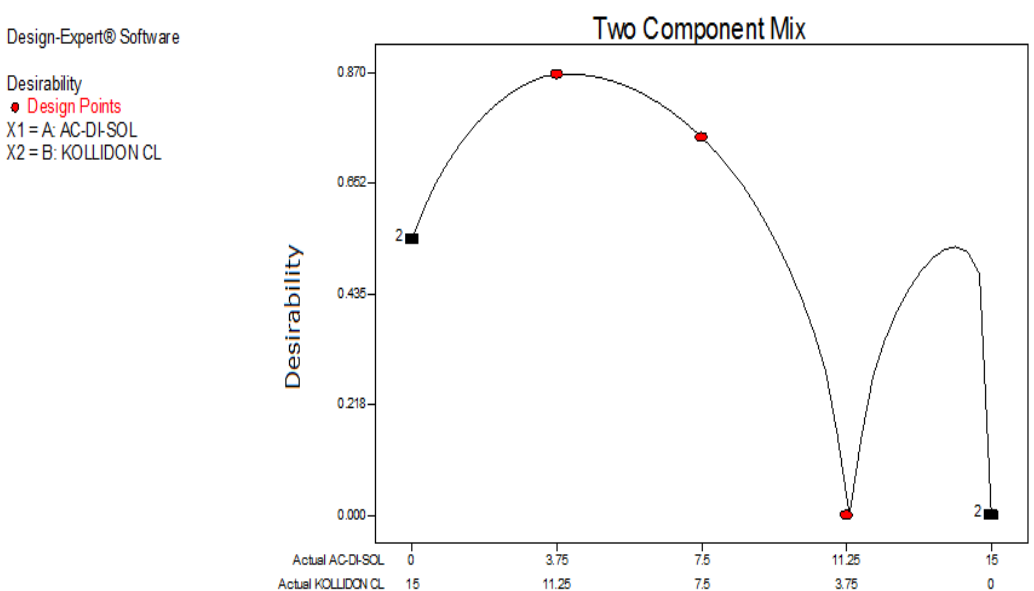

Figure 7. Superimposed contour plot of tablet friability, wetting time, disintegration time, and \% cumulative of drug release after $60 \mathrm{~s}$

of action become more rapid. On the other hand, the combination use of both superdisintegrants decelerated disintegration time, indicated by the negative sign in the equation.

\section{Effect of independent variables on drug} dissolution

F1-F5 were subjected for drug release study. Figure 5 shows dissolution profile of nanoparticle meloxicam ODT during the $1^{\text {st }}$, $3^{\text {td }}, 5^{\text {th }}, 10^{\text {th }}, 15^{\text {th }}, 20^{\text {th }}, 25^{\text {th }}$, and $30^{\text {th }}$ min. It can 
be seen that in the first minute a great amount of meloxicam was released, approximately $47.08-89.5 \%$, because of the presence of superdisintegrant(s). Ac-Di-Sol has double mechanisms, that are absorbing water and rapidly swelling, whereas Kollidon CL has hydrophilic property, quickly dispersed, and swells immediately after contacting water without forming a gel. Moreover, Kollidon CL has a porous structure that increases disintegrating time and accelerates tablet wetting by water (Mohamed et al., 2012). Based on the cumulative dissolution of nanoparticle meloxicam ODT in 60 seconds in Table III, it can be made into an equation (Table IV). The contour plot can be seen in figure 6 .

Cubical model analysis showed a significant relationship with $\mathrm{F}$ value $=7521.07$ and $\mathrm{p}$-value $=0.0085$. The equation (10) depicts the influence of each factor and the interaction between Ac-Di-Sol and Kollidon CL. Single use of superdisintegrant increased the amount of meloxicam released after 60 seconds, while the combination use of superdisintegrants decreased the percent cumulative drug release. In the equation 10 , the coefficient of Ac-Di-Sol was the highest and therefore ODT formula containing this superdisintegrant had the highest drug release. This finding was in line with friability and disintegrating tests where ODT formula with only Ac-Di-Sol superdisintegrant provided a dominant response to the increase of friability and disintegrating time.

\section{Determination of optimum formula}

The results from the studies of friability, wetting time, disintegrating time, and \% cumulative drug release after 60 seconds were analyzed with Design Expert and resulted in a graph of mixed components, as showed in Figure 7. Three types of goal (range, maximize, and minimize) were defined for each parameter (Table V).

The optimization demonstrated that the optimum formula for nanoparticle meloxicam ODT had the proportion of Ac-DiSol:Kollidon CL of $4.05 \mathrm{mg} \quad: 10.95 \mathrm{mg}$, respectively, with desirability of 0.867 . This optimum formula was verified further by re- formulating the ODT and evaluating its physical characteristics, including the friability, wetting time, disintegration time, and \% cumulative of meloxicam dissolved after 60 seconds.

No significant differences were found between predicted versus observed values across four parameters (Table VI), thus proving the accuracy of current design.

\section{CONCLUSION}

The present study asserted that evaluation of the effects of the use of different superdisintegrants in terms of type and proportion on the characteristics of ODT formulas is important. The combination of AcDi-Sol of $4.05 \mathrm{mg}$ and Kollidon CL of $10.95 \mathrm{mg}$ produced optimum ODT-based on the evaluation of tablet characteristics, including the friability, wetting time, disintegration time, and $\%$ cumulative of meloxicam dissolved after 60 seconds. There was no difference between predicted value and observed value after verification.

\section{ACKNOWLEDGEMENT}

The authors would like to thank the Directorate of Higher Education of the Republic of Indonesia for the funding granted for this research through the 2015 Hibah Bersaing scheme.

\section{REFERENCES}

Ahmed I., Aboul-Einen M., 2007. In vitro and in vivo evaluation of a fast disintegrating lyophylized drug emulsion tablet containing griseofulvin. Eur. J. Pharm. Sci. 32:58-68.

Banker GS., Anderson NR., 1986. Tablets. In Lachman L., Lieberman HA., Kanig JL., editors. The theory and practice of industrial pharmacy. $3^{\text {th }}$ edition. Philadelphia. PA. Lea \& Febiger. p 293-345.

Bhowmik D., Chiranjib B., Krishnakanth, Pankaj, Margret R., 2009. Fast Dissolving Tablet: An Overview. J. Chem. Pabrmaceut. Res. 1(1): 163-177.

Bustos FM., Soto ML., Martinez ESM., Morales JJZ., Velez-Medina JJ., 2007. Effects of high energy milling on some functional properties of Jicama starch (pachyrrhizus 
crosus L.urban) and cassava starch (Mannihot esculenta crantz), Journal of food engineering. 78:1212-1220.

Camarco WD., Ray, Drufftner A., 2006. Selecting superdisintegrants for orally disintegrating tablet formulations. Pharm. Tech. supplement. s28-s37.

Elbary AA., Ali AA., Abond HM., 2012. Enhanced dissolution of meloxicam from orodispersible tablets prepared by different methods.Bulletin of faculty of pharmacy Cairo university.50(2) pp:89-97.

Galal EL., Mahrouk, Aboul-Einen M., Adel N., 2009. Formulation and evaluation of meloxicam orally dispersible capsules. Asian J. Pharm. Sci. 4(1):8-22.

Gohel M., Patel M., Amin A., Agrawal R., Dave R., Bariya N., 2004. Formulation design and optimization of mouth dissolve tablets of nimesulide using vacuum drying technique. AAPS Pharm.Sci.Tech. 5(3):36.

Hirani JJ., Rathod DA., Vadalla KR., 2009. Orally disintegrating tablets: A review.Trop.J.Pharm.Res. 8(2):161-172

Indonesia Pharmacope.1979.3 th edition. Health Department of Republic Indonesia.Jakarta

Indonesia Pharmacope.2014.5th edition. Health Department of Republic Indonesia.Jakarta

Kornblum SS., Stoppak SB., 1973. A new tablet disintegrating agent:crosslinked polyvinylpyrrolidone. J.Pharm.sci. 62, 4349

Kosek T., Onishi H., Takahashi Y., Uchida M., Machida Y., 2008. Development of Novel Fast-Disintegrating Tablets by Direct Compression Using Sucrose Stearic Acid Esters as A DisintegrationAccelerating Agent. Chem. Pharm. Bull. 56(10): 1384-1388.

Kulkarni SV, Kumar R, Nikunj P., Rao S., Ramesh B, Kumar A., 2011. Formulation and evaluation of fast disintegrating meloxicam tablets and its comparison with marketed produck. Int.J.Pharm.Pharm.Sci. 3(1) pp 91-93.

Lachman L., Liebermann HA., Kanig JI., 1994. The theory and practice of industrial pharmacy. $3^{\text {th }}$ edition.UI Press, Jakarta.645
Mohamed MB., Talari MK., Tripathy M., Majeed ABA., 2012. Pharmaceutical application of crospovidone:A review. IJDFR. 3(1), 3-28.

Möschwitzher J., Müller RH., 2007. Drug Nanocrystals-The Universal Formulation Approach for Poorly Soluble Drugs. In: D. Thassu, M. Deleers dan Y. Pathak (eds). Nanoparticulate Drug Delivery Systems. New York: Informa Healthcare USA, Inc. Pages 72-73, 77-78.

Panigrahi R., Behera SA., 2010. A review on fast dissolving tablets.(ONLINE) available at:http://www.webmedcentral.com/artic le-view/809 (accessed 15 February 2015).

Quadir A., Kolter K., 2006. A comparative study of current superdisintegrants. Pharm.Technol. 38-42.

Rahman Z., Zidan AS., Khan MA., 2010. Resperidone solid dispersion for orally disintegrating tablet:its formulation design and non-destructive methods of evaluation. Int.Journal of pharmaceutics. 400(1):pp49-58.

Saleem MA., Bala S., 2010. Formulation and Evaluation of Meloksikam Solid Dispersion Incorporated Topical Gels. IJPBS, Vol 1(3): 1-9.

Samprasit W., Akkaramongkolporn P., Ngawhiruhpat T., Rojanavata T., Opanasopit P., 2013. Meloxicam tastemasked oral disintegrating tablet with dissolution enhanced by ion exchange resins and cyclodextrin. AAPS.PharmSciTech.14(30:1118-1128.

Sharma K., Pfister WR., Gosh TK., 2005. Quick dispersing oral drug delivery systems. In:TK Gosh, Pfister WR (eds).drug Delivery to the oral cavity:Molecules to market, Bola raton:Taylor \& Francis Group.pp:262-263.

Singhvi G., Gampa G., Yadav N., Kumar V., Ukawala R., 2013. Design and evaluation of rapidly disintegrating tablets of racecadotril with enhanced in vitro dissolution achieved by solid dispersion technique. Indian.J.Pharmacent. edu.Res. 47(3). 
Tanuwijaya J., Karsono, Urip H., 2014. Characterization of piroxicam nanoparticles in orally disintegrating tablet (ODT). Int.J.ChemTech.Res. 6(2), 11955-961.

Wiradjaja FS., Saifullah TN., 2015. Optimization of Orally disintegrating tablet (ODT) by inclusions complex between meloxicam and $\beta$-cyclodextrin using Ac-Di-Sol and Kollidon CL as superdisintegrants and Avicel PH 200 as filler binder.Thesis.Faculty of Pharmacy.Gadjah Mada 